Journal of Advanced Research in Fluid Mechanics and Thermal Sciences

\title{
A Thematic Review on Mathematical Model for Convective Boundary Layer Flow
}

\author{
Siti Farah Haryatie Mohd Kanafiah ${ }^{1,2}$, Abdul Rahman Mohd Kasim ${ }^{2, *}$, Syazwani Zokri ${ }^{3}$, Nur Syamilah \\ Arifin ${ }^{4}$
}

Faculty of Computer and Mathematics Sciences, Universiti Teknologi MARA (UiTM), Cawangan Kelantan, Malaysia

2 Centre for Mathematical Sciences, Universiti Malaysia Pahang, Universiti Malaysia Pahang (UMP), Gambang, Pahang, Malaysia

3 Faculty of Computer and Mathematics Sciences, Universiti Teknologi MARA (UiTM), Cawangan Terengganu, Kampus Kuala Terengganu, Malaysia

4 Faculty of Computer and Mathematical Sciences, Universiti Teknologi MARA (UiTM), Cawangan Johor, Kampus Pasir Gudang, Masai, Johor, Malaysia

\section{ARTICLE INFO}

\section{Article history:}

Received 10 May 2021

Received in revised form 12 July 2021

Accepted 20 July 2021

Available online 27 August 2021

\section{Keywords:}

Convective boundary layer; fluid flow; ATLAS.ti 8; thematic review

\section{ABSTRACT}

Convection refers to the heat transfer that occurs between moving fluid and surface at a different temperature. Nowadays, there has been a great deal of interest in the convective boundary layer fluid flow problems. Despite its popularity, the review paper discussing the mathematical model for various fluid types regarding various geometry and boundary conditions has been observed to fall short. This review paper adopts a thematic review based on the mathematical model captured in published fluid flow problems from 2015 until 2020. The articles were analysed using thematic analysis ATLAS.ti 8 software. Using keyword search and filtering criteria from Scopus and Web of Science (WOS) databases, 198 peer-reviewed journal articles were identified. However, after the exclusion and inclusion processes, only 50 articles were reviewed as final articles. The thematic review of these articles has further identified 120 initial codes characterising the mathematical model, grouped into 7 clusters: Viscoelastic, Williamson, Casson, Brinkman, Jeffrey, Nanofluid and hybrid Nanofluid. The report from the code-to-document in ATLAS.ti 8 found that the boundary condition, geometry and method were highlighted in the literature. The outcomes of this study will benefit the future research direction to identify the gap for future studies, specifically in extending the mathematical model for fluid flow problems as well as choosing the suitable geometry and boundary condition.

\section{Introduction}

Convection refers to the heat transfer generated by the random motion of molecules and the energy transmitted by fluid's motion. Additionally, the boundary condition and surface geometry are the dual elements that influence the heat transfer process. Due to its significance in many industrial

\footnotetext{
* Corresponding author.

E-mail address: rahmanmohd@ump.edu.my
}

https://doi.org/10.37934/arfmts.86.2.107125 
and technical applications, interest in convective boundary layer flow problems has increased substantially over the year.

About a dozen articles have been published on convective boundary layer problems in various fluid types with different surface geometry. For example, the fluid flow problem along a flat plate [14], fluid flow over the circular cylinder [5-7], fluid flow over a stretching sheet [8-12], fluid flow over a sphere [13-15] and fluid flow over an inclined stretching sheet [16-18].

The theoretical investigations in non-Newtonian fluids are more challenging due to the complexity of their constitutive equations. A non-Newtonian fluid is a fluid that does not obey Newton's law in which the viscosity will change to either liquid or more solid under stress. The most frequently highlighted mathematical model for non-Newtonian in the literature comprehend the Jeffrey fluid [19-22], Nanofluid [23-25], Viscoelastic fluid[26-28], Brinkman fluid [29-31], Casson fluid [32-34] and Williamson fluid models [35-36]. Even though the convective boundary layer flow has been widely explored, the review paper on different mathematical models with dissimilar boundary conditions, surface geometry, and method has been very scarce.

Therefore, the underpinning of this paper is to perform a systematic review of the mathematical model discussed in convective boundary layer flow. The discussion will be specifically directed to boundary condition, surface geometry and methods used in each problem based on the following research question; What are the mathematical models of the non-Newtonian fluid on convective boundary layer flow being discussed in the publication from 2015 to 2020 ?

\section{Thematic Review Process}

This section discusses in detail the materials and methods used in this study. The main concept of this study is the thematic review process introduced by [37], implemented using ATLAS.ti 8 software. He applied the thematic analysis technique in the literature review. The thematic analysis identifies the trend and constructs the themes through detailed reading on the topic [38]. In this study, the first step is defining the pattern and constructing a mathematical model category to understand the trend of publication in various countries. The research concept is to analyse and interpret the findings on the types of a mathematical model in the convective boundary layer for recommendations of future study. Literature selection was carried out according to different selection criteria, which are 1) publication from 2015-2020, 2) has at least keyword(s) of the convective boundary layer or fluid flow, and 3) focus on a mathematical model. The decision to limit the fluid type was made to help define the model used in fluid flow problems. The literature discovery was conducted using the search strings in the Scopus and WOS database, as illustrated in Table 1.

Table 1

Search strings from Scopus and WOS

\begin{tabular}{lll}
\hline Database & Keyword & Result \\
\hline Scopus & TITLE-ABS-KEY (“Convective Boundary Layer” AND fluid flow) & 129 articles \\
& PUBYEAR (2015-2020) & \\
WOS & TITLE-ABS-KEY ( "Convective Boundary Layer" AND fluid flow) & \multirow{2}{*}{69 articles } \\
& PUBYEAR (2015-2020) & \\
\hline
\end{tabular}

In this study, the systematic review of articles was performed in the Scopus and WOS search to identify the mathematical model of the convective boundary layer. The inclusion and exclusion criteria are carried out in the current study, as displayed in Figure 1. The initial search was made with 129 (Scopus) and 69 (WOS) articles. However, 125 papers have been removed and not matched due to their premature outcomes, while 23 overlapping articles also have been excluded. Some of these 
articles were incomplete, or the full articles cannot be accessed and have a broken link. Therefore, the final paper to be reviewed is 50 articles, including conference proceeding and journals.

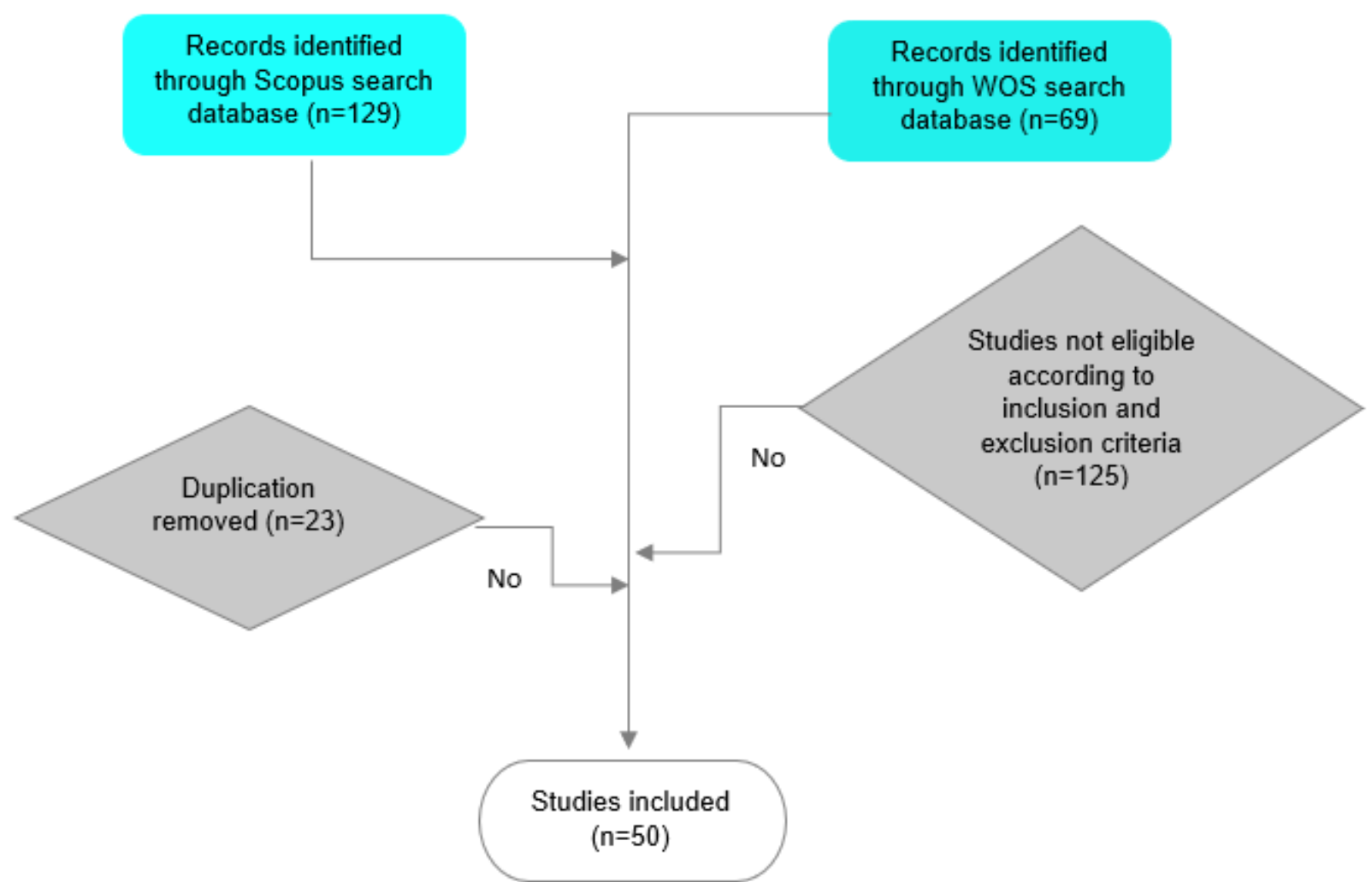

Fig. 1. Inclusion and exclusion criteria in the thematic review

The articles were uploaded in the ATLAS.ti 8 as primary documents, grouped into author, issue number, periodical, publisher and year of publication. In the first round, the initial coding resulted in 120 codings and later was categorised into seven main categories: Viscoelastic, Williamson, Casson, Brinkman, Jeffrey, Nanofluid, and hybrid Nanofluid models. In a thematic review, clustering the initial coding into the group classifies a common code under a similar category. However, it is also common for a code to belong to several categories, namely code group.

\section{Past Studies on Convective Boundary Layer Flow}

In this section, the tables and figures are displayed based on the following subject: journals and year, authors and fluid models, country and year as well as fluid models and year. Firstly, these research strings are directly referenced in the identified 50 articles through several journals listed in Table 2. As can be seen from the table, many publications highlighted the convective boundary layer fluid flow problems in 2017. The trends of publication are shown in a normal distribution. It is also noted that the involved journals are not necessarily heat and fluid-related journals such as Advanced Powder Technology, AIP Conference Proceedings and Journal of Symmetry. 


\section{Table 2}

Reviewed articles based on journals and year

\begin{tabular}{|c|c|c|c|c|c|c|}
\hline \multirow[t]{2}{*}{ Journals } & \multicolumn{6}{|l|}{ Year } \\
\hline & 2015 & 2016 & 2017 & 2018 & 2019 & 2020 \\
\hline Advanced Powder Technology & 1 & & 1 & 1 & & \\
\hline Ain Shams Engineering Journal & & 1 & & & & \\
\hline AIP Conference Proceedings & & 1 & 1 & & & \\
\hline American Journal of Heat and Mass Transfer & & & 1 & & 1 & \\
\hline Archives of Thermodynamics & & & & & 1 & \\
\hline ARPN Journal of Engineering and Applied Sciences & & 1 & & & & \\
\hline Canadian Journal of Physics & 1 & & & & & \\
\hline Chemical Engineering Science & & & 1 & & & \\
\hline Engineering Computations (Swansea, Wales) & & & 1 & & & \\
\hline Engineering Science and Technology, an International Journal & & & 1 & & & \\
\hline Frontiers in Heat and Mass Transfer & & & 1 & & & \\
\hline International Journal of Ambient Energy & & & & 1 & & \\
\hline International Journal of Applied and Computational Mathematics & & & 1 & & & \\
\hline International Journal of Numerical Methods for Heat and Fluid Flow & & 1 & 2 & 1 & 1 & \\
\hline IOP Conference Series: Materials Science and Engineering & & & 1 & & & \\
\hline Journal of Aerospace Engineering & 1 & & & & & \\
\hline Journal of Applied Fluid Mechanics & & 1 & & & & \\
\hline Journal of Engineering Physics and Thermophysics & 1 & & & & & \\
\hline Journal of King Saud University - Science & & & & & 1 & \\
\hline Journal of the Brazilian Society of Mechanical Sciences and Engineering & & & 1 & & & \\
\hline Journal of Thermal Analysis and Calorimetry & & & & 1 & & \\
\hline MATEC Web of Conferences & & & & 1 & & \\
\hline Materials Today: Proceedings & & & 1 & 1 & & \\
\hline Mathematical Modelling of Engineering Problems & & & & & & 1 \\
\hline Physics Letters, Section A: General, Atomic and Solid State Physics & & & & 1 & & \\
\hline PloS ONE & 1 & & & & & \\
\hline Procedia Engineering & 1 & 1 & & & & \\
\hline $\begin{array}{l}\text { Proceedings of the Institution of Mechanical Engineers, Part N: Journal } \\
\text { of Nanomaterials, Nanoengineering and Nanosystems }\end{array}$ & & & 1 & & & \\
\hline Sains Malaysiana & & & & 1 & & \\
\hline Scientia Iranica & & & 1 & 1 & & \\
\hline Symmetry & & & & & 1 & \\
\hline Thermal Science & 1 & & & 1 & & \\
\hline Water & & & & & & 1 \\
\hline Journal of Mechanical Engineering Science & & & & & & 1 \\
\hline Case Studies in Thermal Engineering & & & & & & 1 \\
\hline Mathematics & & & & & & 1 \\
\hline Heliyon & & & & & 1 & \\
\hline Chinese Journal of Physics & & & & 1 & & \\
\hline Totals & 7 & 6 & 15 & 11 & 6 & 5 \\
\hline
\end{tabular}

Next, research articles were analysed in an iterative process as tabulated in Table 3 . The comparison was made according to its similarity and differences to ensure consistency in the resulting sub-categories. These articles were assigned to the types of fluid models. It was noticed that the Nanofluid model, which is Buongiorno and Tiwari and Das, are very popular models among the considered articles. Recently, the hybrid Nanofluid model has been extensively explored by researchers. 
Table 3

The classification of authors based on a fluid model

\begin{tabular}{|c|c|c|c|c|c|c|c|c|}
\hline \multirow[t]{2}{*}{ Author } & \multicolumn{8}{|l|}{ Model } \\
\hline & $\begin{array}{l}\text { Brink- } \\
\text { man }\end{array}$ & $\begin{array}{l}\text { Buongi- } \\
\text { orno }\end{array}$ & $\begin{array}{l}\text { Cas- } \\
\text { son }\end{array}$ & $\begin{array}{l}\text { Jeff- } \\
\text { rey }\end{array}$ & $\begin{array}{l}\text { Tiwari } \\
\text { das }\end{array}$ & $\begin{array}{l}\text { Visco- } \\
\text { elastic }\end{array}$ & $\begin{array}{l}\text { William- } \\
\text { son }\end{array}$ & $\begin{array}{l}\text { Hybrid } \\
\text { Nanofluid }\end{array}$ \\
\hline Thumma et al., [39] & & & & & 1 & & & \\
\hline Thumma et al., [40] & & & & & 1 & & & \\
\hline Sravanthi [41] & & & & & 1 & & & \\
\hline Kumar \& Kumar [42] & & & & & 1 & & & \\
\hline Sohail et al., [3] & & 1 & & & & & & \\
\hline Reddy [43] & & & 1 & & & & & \\
\hline Rajesh et al., [44] & & & & & 1 & & & \\
\hline Narahari et al., [45] & & 1 & & & & & & \\
\hline Narahari et al., [46] & & 1 & & & & & & \\
\hline Metri et al., [47] & & & & & & 1 & & \\
\hline Makinde et al., [48] & & 1 & & & & & & \\
\hline Krishna \& Reddy [49] & 1 & & & & & & & \\
\hline Izani \& Ali [50] & & & & 1 & & & & \\
\hline Devi \& Suriyakumar [51] & & & & & 1 & & & \\
\hline Aziz et al., [26] & & & & & & 1 & & \\
\hline Archana et al., [52] & & 1 & & & & & & \\
\hline Akbar et al., [53] & & 1 & & & & & & \\
\hline Ahmed et al., [54] & & & 1 & & & & & \\
\hline Ahmed et al., [55] & & 1 & & & & & & \\
\hline Reddy \& Shankar [56] & & 1 & & & & & & \\
\hline Uddin et al., [57] & & 1 & & & & & & \\
\hline Al-Sharifi et al., [22] & & & & 1 & & & & \\
\hline Kumar \& Kumar [58] & & & & & 1 & & & \\
\hline Saranya et al., [59] & & & 1 & & & & & \\
\hline Reddy [60] & & & 1 & & & & & \\
\hline Parmar [61] & & & & & & & 1 & \\
\hline Nayak et al., [62] & & 1 & & & & & & \\
\hline Maleque [63] & & & 1 & & & & & \\
\hline Khan et al., [64] & & 1 & & & & & & \\
\hline Isa et al., [65] & & & 1 & & & & & \\
\hline Hashim et al., [66] & & & & & & & 1 & \\
\hline Eswaramoorthi et al., [67] & & & & & & 1 & & \\
\hline Dinarvand et al., [68] & & & & & 1 & & & \\
\hline Dinarvand et al., [69] & & 1 & & & & & & \\
\hline Basir et al., [70] & & 1 & & & & & & \\
\hline Arifin et al., [36] & & & & & & & 1 & \\
\hline Zokri et al., [20] & & & & 1 & & & & \\
\hline Gangadhar et al., [71] & & 1 & & & & & & \\
\hline Tlili [72] & & & & 1 & & & & \\
\hline Siyal et al., [73] & 1 & & & & & & & \\
\hline Chu et al., [74] & & & & & & & & 1 \\
\hline Suganya et al., [75] & & & & & & & & 1 \\
\hline U. Khan et al., [76] & & & & & & & & 1 \\
\hline Waini et al., [77] & & & & & & & & 1 \\
\hline Waini et al., [78] & & & & & & & & 1 \\
\hline Manjunata et al., [79] & & & & & & & & 1 \\
\hline Junoh et al., [80] & & & & & & & & 1 \\
\hline Rostaimi et al., [25] & & & & & & & & 1 \\
\hline Yousefi et al., [81] & & & & & & & & 1 \\
\hline Mehryan et al., [82] & & & & & & & & 1 \\
\hline Totals & 2 & 14 & 6 & 4 & 8 & 3 & 3 & 10 \\
\hline
\end{tabular}


After that, the trends were analysed following the country and year of the conducted study, as exhibited in Table 4. The trend was seen as rather popular in India and Malaysia. The publications from other countries are also reported, such as Bangladesh, Egypt, Iran, Pakistan, Saudi Arabia, South Africa, Sweden and China. This shows that trends of convective boundary layer have increased over the varying country with different types of the fluid model.

Table 4

Reviewed articles based on country and year

\begin{tabular}{llllllll}
\hline Country & Year & & & & & \\
\cline { 2 - 8 } & 2015 & 2016 & 2017 & 2018 & 2019 & 2020 & Totals \\
\hline Bangladesh & 0 & 0 & 1 & 0 & 0 & 0 & 1 \\
Egypt & 0 & 0 & 1 & 0 & 1 & 0 & 2 \\
India & 2 & 2 & 7 & 4 & 2 & 2 & 19 \\
Iran & 2 & 0 & 1 & 2 & 0 & 0 & 5 \\
Malaysia & 1 & 2 & 5 & 2 & 2 & 1 & 13 \\
Pakistan & 2 & 1 & 0 & 2 & 0 & 1 & 6 \\
Saudi Arabia & 0 & 0 & 0 & 0 & 1 & 0 & 1 \\
South Africa & 0 & 0 & 0 & 1 & 0 & 0 & 1 \\
Sweden & 0 & 1 & 0 & 0 & 0 & 0 & 1 \\
China & 0 & 0 & 0 & 0 & 0 & 1 & 1 \\
\hline
\end{tabular}

Lastly, in this paper, the mathematical model for convective boundary layer flow problems is discussed over various fluid types. As can be seen from the Table 5, the most popular mathematical model is the Nanofluid model, which is Buongiorno (28\%), and Tiwari and Das (16\%). These two models have attracted more attention in engineering applications for the Nanofluid type over the years. Besides, the Hybrid nanofluid model (20\%) has gained much attraction from 2017 to 2020. It is then followed by Casson (12\%), Jeffrey (8\%), Williamson (6\%), Viscoelastic (6\%) and Brinkman (4\%). The pattern of the mathematical model shows that there is limited work focusing on Williamson, Viscoelastic and Brinkman Models.

Table 5

Reviewed articles based on fluid models and year

\begin{tabular}{|c|c|c|c|c|c|c|c|c|}
\hline \multirow{2}{*}{ Models } & & \multicolumn{7}{|l|}{ Year } \\
\hline & & 2015 & 2016 & 2017 & 2018 & 2019 & 2020 & Totals \\
\hline Brinkman & & 0 & 0 & 0 & 2 & 0 & 0 & 2 \\
\hline \multirow[t]{2}{*}{ Nanofluid } & Buongiorno & 4 & 1 & 4 & 2 & 2 & 1 & 14 \\
\hline & Tiwari and Das & 1 & 1 & 5 & 1 & 0 & 0 & 8 \\
\hline \multicolumn{2}{|l|}{ Casson } & 1 & 1 & 3 & 1 & 0 & 0 & 6 \\
\hline \multicolumn{2}{|l|}{ Jeffrey } & 0 & 2 & 0 & 1 & 1 & 0 & 4 \\
\hline \multicolumn{2}{|l|}{ Viscoelastic } & 1 & 1 & 1 & 0 & 0 & 0 & 3 \\
\hline \multicolumn{2}{|c|}{ Williamson } & 0 & 0 & 1 & 2 & 0 & 0 & 3 \\
\hline \multicolumn{2}{|c|}{ Hybrid Nanofluid } & 0 & 0 & 1 & 2 & 3 & 4 & 10 \\
\hline
\end{tabular}

This final section discusses the mathematical models with the related boundary condition, surface geometry, and method illustrated in figures and tables for every section below.

\subsection{Viscoelastic Model}

Viscoelasticity is the property of materials that exhibit both viscous and elastic properties deformation. Some examples of viscoelastic materials include biopolymers, metals at very high temperatures, and bitumen materials. Cracking happens when the pressure is strongly applied and 
beyond the elastic limit. The study of boundary layer flow and heat transfer of viscoelastic fluid has been addressed in many engineering applications. Figure 2 shows the network diagram of the Viscoelastic model, while the summary of previous research topic based on boundary condition, surface geometry and method are listed in Table 6. Eswaramoorthi et al., [67] studied the problem of unsteady three-dimensional magnetohydrodynamic (MHD) in stretching surface with constant wall temperature (CWT) boundary condition. They derived the analytical solutions using Homotopy Analysis Method (HAM). In another study of MHD mixed convection boundary layer embedded in a porous medium over a similar geometry, Metri et al., [47] used two types of the heating process, namely the constant heat flux (CHF) and constant wall temperature (CWT). The numerical solutions were then solved using Runge Kutta Fehlberg Method with shooting technique. Meanwhile, Aziz et al., [26] investigated the effect of aligned MHD on a mixed convective boundary layer past a circular cylinder for the case of Newtonian Heating (NH). They used the Keller Box method to solve the numerical solution.

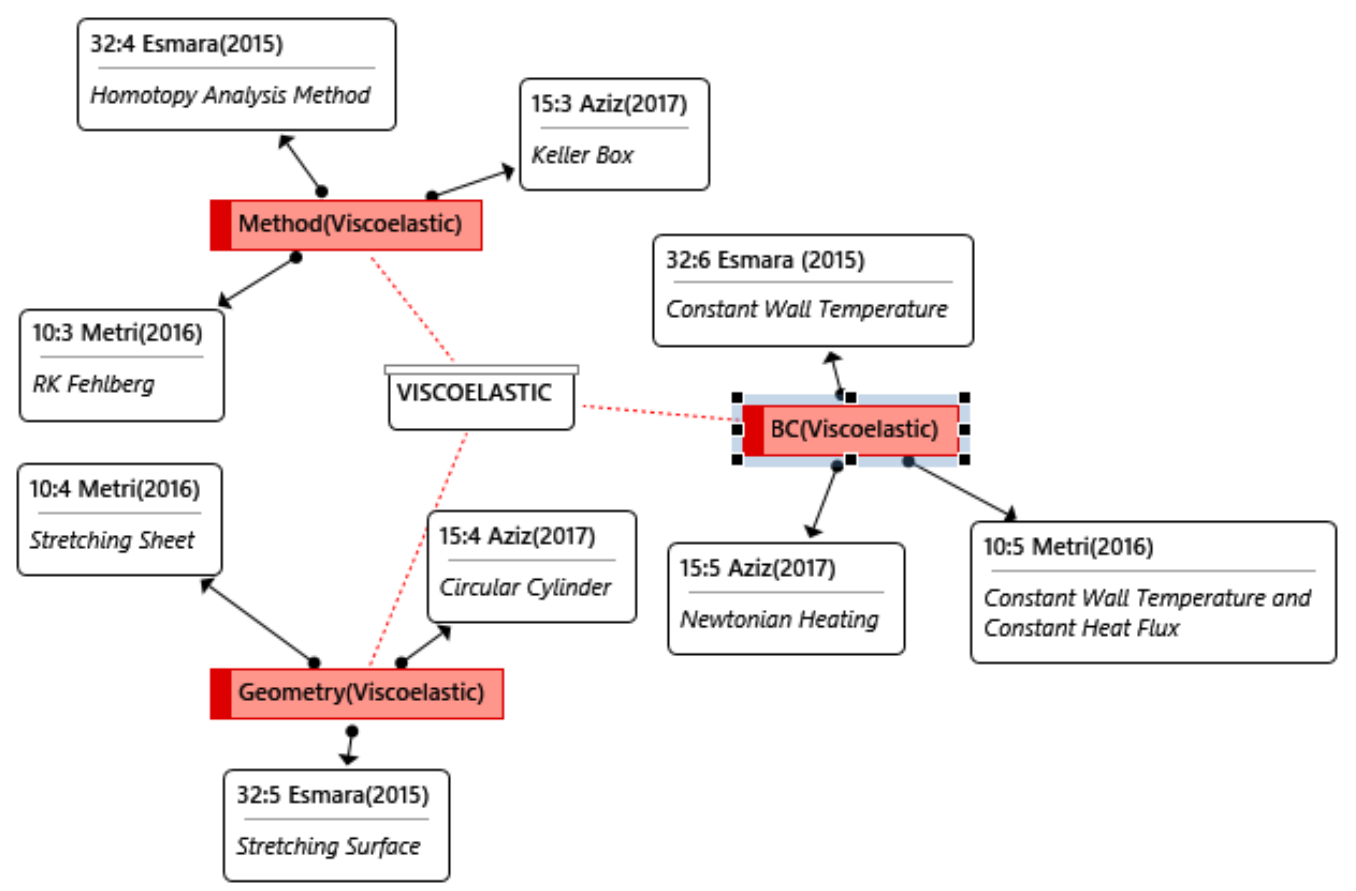

Fig. 2. A network of Viscoelastic model

Table 6

Summary of authors based on boundary condition, geometry, and method

\begin{tabular}{llll}
\hline Authors & Boundary Condition & Geometry & Method \\
\hline Eswaramoorthi et al., [67] & CWT & Stretching Surface & Homotopy Analysis Method \\
Metri et al., [47] & CHF \& CWT & Stretching Surface & Runge Kutta Fehlberg \\
Aziz et al., [26] & NH & Circular Cylinder & Keller Box \\
\hline
\end{tabular}

\subsection{Casson Model}

Casson fluid can be described as a shear-thinning liquid having infinite viscosity at zero shear rate, yield stress below regions with no flow, and zero viscosity at an infinite shear rate Mehta and Dash [83]. Numerous researchers have studied on Casson fluid model owing to its special yield stress characteristic. The overall network diagram of the Casson model is shown in Figure 3, while Table 7 shows the summary of authors based on boundary condition, geometry and method. The investigation involving flow over a stretching sheet with constant wall temperature was conducted 
by many researchers $([54,60,65])$. They used the "built-in" Matlab program (BVP4C), the Shooting method and Runge Kutta $4^{\text {th }}$ order integration, respectively, to solve the numerical solution. In other theoretical studies, Reddy [43] and Maleque [63] investigated the MHD convective boundary layer flow over the inclined stretching surface and vertical plate in the presence of thermal radiation and chemical reaction, respectively. It was noticed that the $C B C$ is rarely used in the recent study. Therefore, Saranya et al., [59]considered the convective boundary condition to investigate steady convective boundary layer flow and heat transfer of base fluids with magnetic/non-magnetic nanoparticles over a flat plate, incorporating non-linear thermal radiation slip effects.

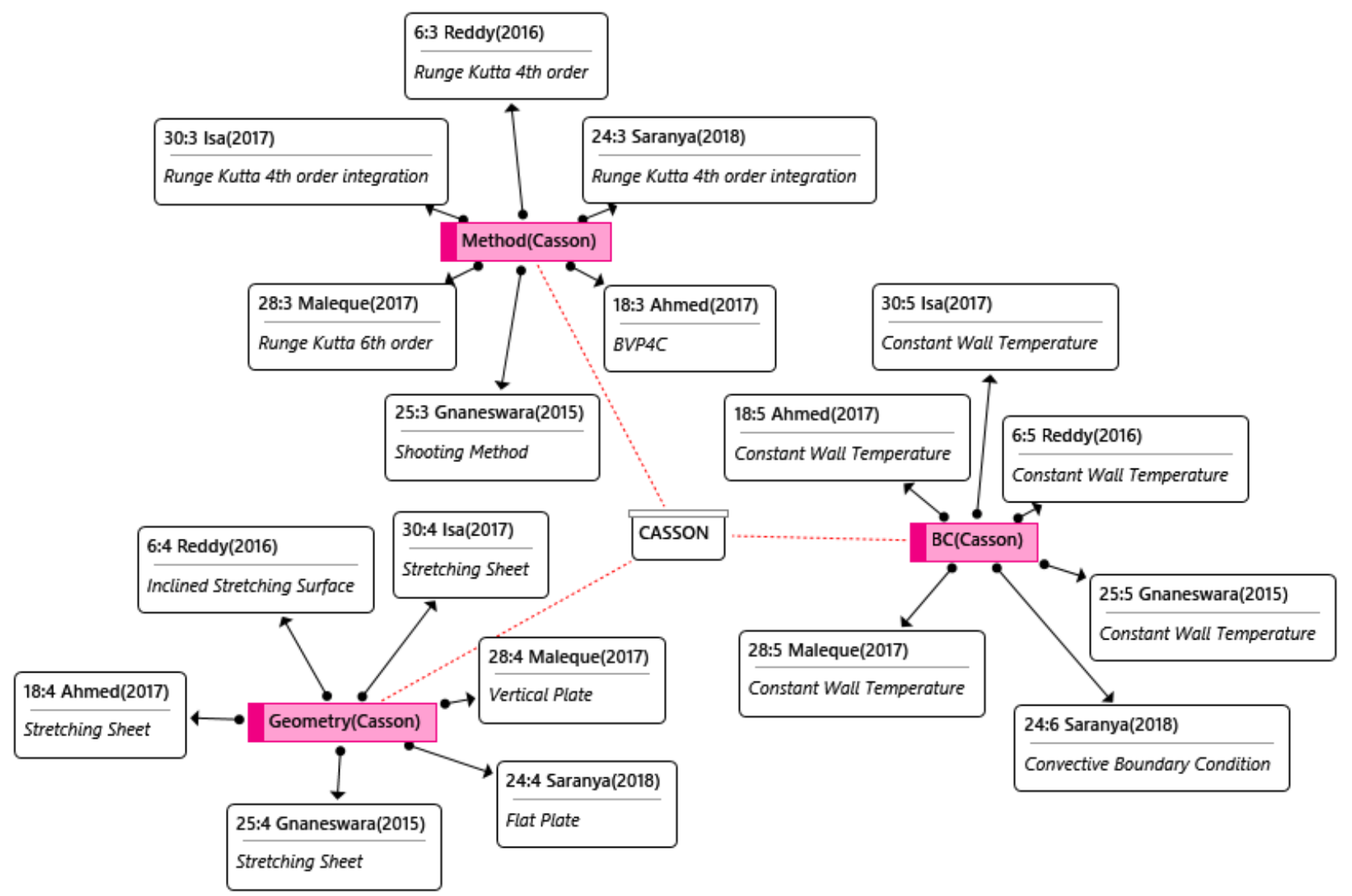

Fig. 3. A network of Casson model

Table 7

Summary of authors based on boundary condition, geometry and method

\begin{tabular}{llll}
\hline Authors & Boundary Condition & Geometry & Method \\
\hline Reddy [60] & CWT & Stretching Sheet & Shooting method \\
Reddy [43] & CWT & Inclined Stretching Sheet & Runge Kutta 4 ${ }^{\text {th }}$ \\
Ahmed et al., [54] & CWT & Stretching Sheet & BVP4C \\
Maleque [63] & CWT & Vertical Plate & Runge Kutta 6 6 \\
Isa et al., [65] & CWT & Stretching Sheet & Runge Kutta 4 ${ }^{\text {th }}$ Integration \\
Saranya et al., [59] & CBC & Flat Plate & Runge Kutta 4th Integration \\
\hline
\end{tabular}

\subsection{Williamson Model}

Figure 4 shows a network diagram of the Williamson fluid model. It is characterised as a nonNewtonian fluid with a shear-thinning property where the viscosity decreases with an increasing shear stress rate. According to Williamson [84], yield stress does not influence fluid behaviour and cannot be molded. Several studies on the flow behaviour of Williamson fluid under the thermal 
condition of $\mathrm{CBC}$ were considered by Arifin et al., [36], Hashim et al., [61] and Parmar [66], as can be seen in Table 8. They applied different numerical solutions such as Runge Kutta Fehlberg $4^{\text {th }}$ and $5^{\text {th }}$ order and Runge Kutta Integration. Arifin et al., [36] analysed Williamson fluid on the convective boundary layer flow and heat transfer over a horizontal stretching sheet. Meanwhile, Hashim et al., [66] investigated the effect of thermal radiation due to an expanding cylinder. They revealed that friction and heat transfer coefficients are greatly increased by the magnetic parameter for upper branch solutions. In another study, Parmar [61] discussed the effect of MHD Williamson fluid over an inclined stretching sheet. Therefore, it can be concluded that the most used boundary condition in the literature is $\mathrm{CBC}$. Hence, other boundary condition can be considered for future study with different geometry and effect.

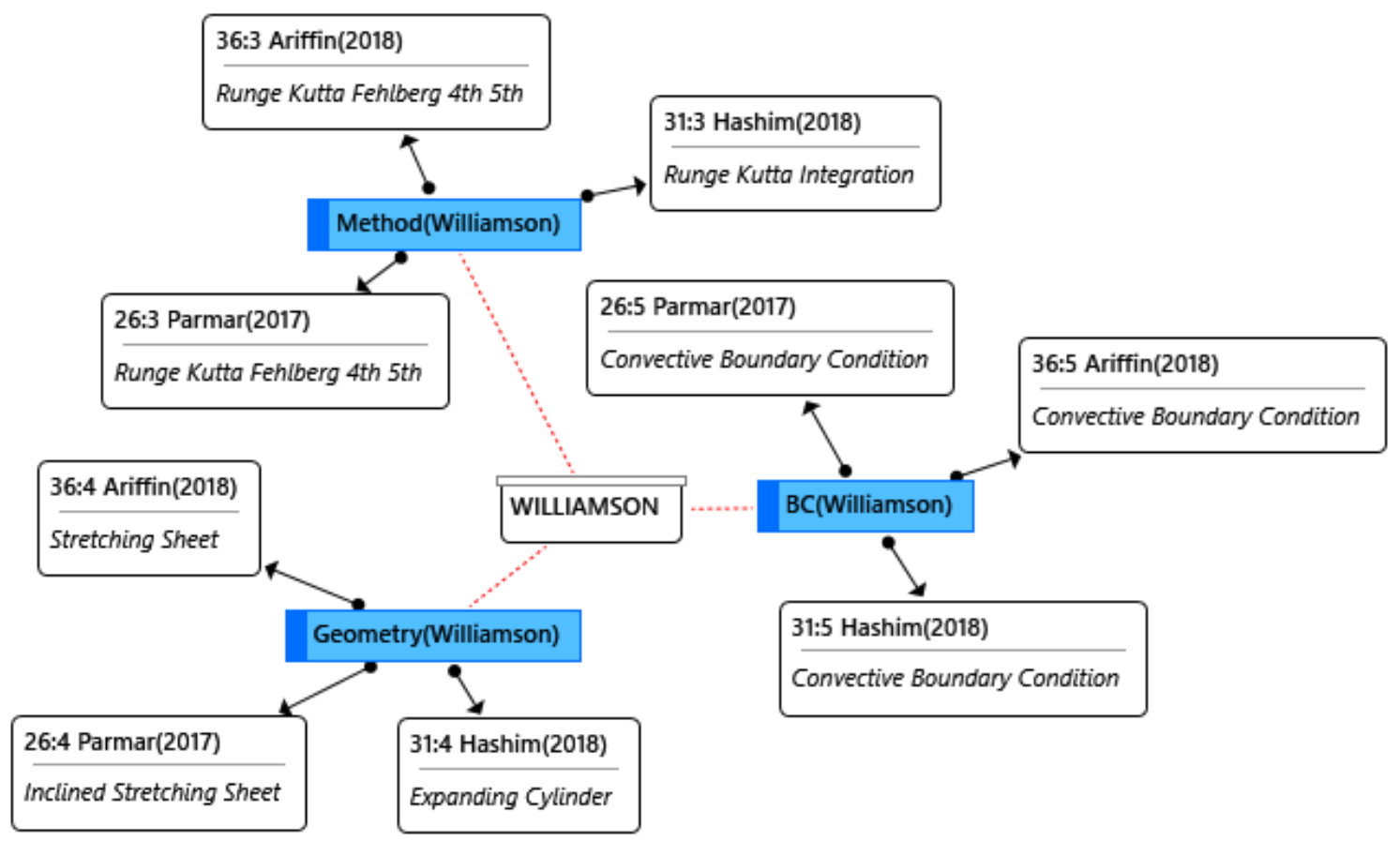

Fig. 4. A network of Williamson model

Table 8

Summary of authors based on boundary condition, geometry and method

\begin{tabular}{llll}
\hline Authors & Boundary Condition & Geometry & Method \\
\hline Parmar [61] & CBC & Inclined Stretching Sheet & Runge Kutta Fehlberg $4^{\text {th }} 5^{\text {th }}$ \\
Hashim et al., [66] & CBC & Expanding Cylinder & Runge Kutta Integration \\
Arifin et al., [36] & CBC & Stretching Sheet & Runge Kutta Fehlberg $4^{\text {th }} 5^{\text {th }}$ \\
\hline
\end{tabular}

\subsection{Jeffrey Model}

The Jeffrey fluid model can explain the stress relaxation property of non-Newtonian fluids. It is also known as the relaxation and retardation time which cannot be defined in the normal viscous fluid model. Figure 5 illustrated a network diagram of the Jeffrey Model. The flow induced by various surfaces such as stretching sheet, inclined stretching sheet, exponential stretching and horizontal circular cylinder have been considered by Zokri et al., [20], Al-Sharifi et al., [22], Izani \& Ali [50] and Tlili [72], as can be seen in Table 9. The most frequently highlighted boundary condition in the literature is the CWT and was solved using different methods such as Keller Box, Quasi linearisation 
and Runge Kutta Fehlberg $4^{\text {th }} 5^{\text {th }}$ order. Based on this review, it can be observed that very few researchers used $C B C$ in their problems.

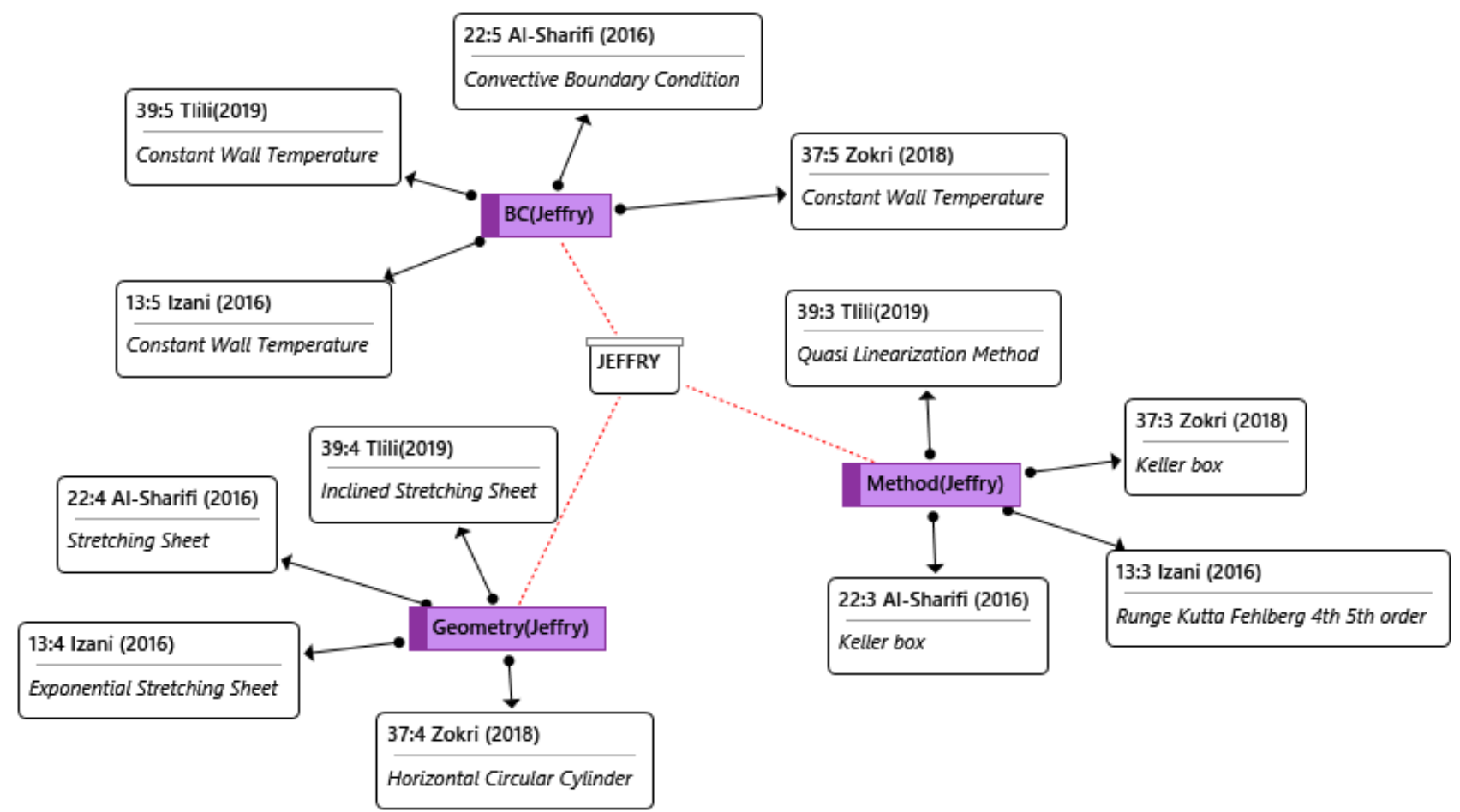

Fig. 5. A network of Jeffrey model

Table 9

Summary of authors based on boundary condition, geometry and method

\begin{tabular}{llll}
\hline Authors & Boundary Condition & Geometry & Method \\
\hline Izani \& Ali [50] & CWT & Exponential Stretching Sheet & Runge Kutta Fehlberg $4^{\text {th }}$ th $^{\text {th }}$ \\
Al-Sharifi et al., [22] & CBC & Stretching Sheet & Keller Box \\
Zokri et al., [20] & CWT & Horizontal Circular Cylinder & Keller Box \\
Tlili [72] & CWT & Inclined Stretching Sheet & Quasi Linearization \\
\hline
\end{tabular}

\subsection{Brinkman Model}

The overall network diagram of the Brinkman model is illustrated in Figure 6 . It describes the incompressible flow in porous media where momentum transport by shear stress in the fluid is crucial. The model considers the viscous transport, momentum balance and introduces velocity in the spatial direction as the dependent variable. Based on Table 10, Krishna \& Reddy [49] studied the MHD free convection in a boundary layer fluid flow through a porous medium over a moving infinite vertical plate by considering radiation and mass transfer. They used the $\mathrm{CBC}$ and solved the problem numerically using Runge Kutta $4^{\text {th }}$ order. Another study in a porous medium by Siyal et al., [73] discussed how the heat flow changes due to temperature or time on the rheology of magnetohydrodynamic Brinkman fluid over the oscillation heated plate subjected to CWT. They analysed the analytical solution using the Laplace Transform Technique. The Brinkman model is applicable for high porous surface and important in numerous engineering application. However, limited researchers have been working on this Brinkman fluid type. 


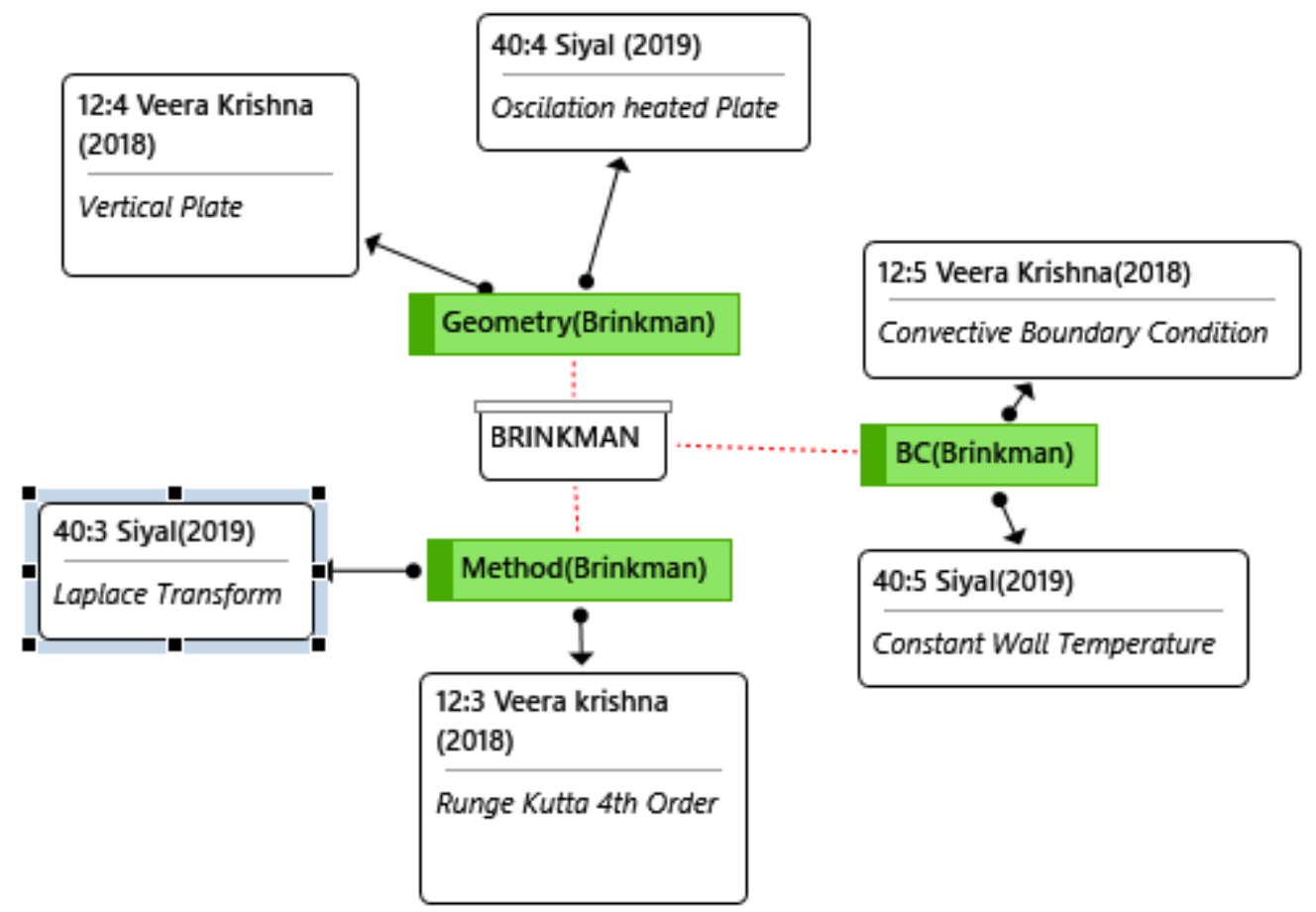

Fig. 6. A network of Brinkman model

Table 10

Summary of authors based on boundary condition, geometry and method

\begin{tabular}{llll}
\hline Authors & Boundary Condition & Geometry & Method \\
\hline Krishna \& Reddy [49] & CBC & Vertical Plate & Runge Kutta 4 \\
Siyal et al., [73] & CWT & Oscillation Heated Plate & Laplace Transform \\
\hline
\end{tabular}

\subsection{Nanofluid Models}

\subsubsection{Tiwari and Das}

Tiwari and Das's model is one of the mathematical models for nanofluid. It takes into consideration the impact of the volume fraction of nanoparticles. The model ignores the velocity slip effect of nanoparticles, which is important in describing the existence of nanoparticles in the base fluid. Several studies in the flow analysis for nanoparticles are based on this model, as portrayed in Figure 7 and listed in Table 11. Thumma et al., [39] considered water-based nanofluids containing metallic nano-particles to investigate the transient dissipative magnetohydrodynamic double diffusive free convective boundary layer flow passing the rotating vertical plate. They used the CWT and solved using the finite element method in numerical computation. Another study by Thumma et al., [40] applied the same boundary condition and method focusing on MHD free convective boundary layer flow of nanofluids but in different geometry. It moves inclined porous plate by considering temperature and concentration gradients with suction effects. These two studies are relevant to high temperature rotating chemical engineering systems. Based on Table 11, most of them are using CWT with various surface geometry and effect. However, Sravanthi [41], used the $\mathrm{CHF}$ to study axisymmetric mixed convective boundary layer flow of a nanofluid past a stretching vertical circular cylinder in the presence of non-linear radiative heat flux. The different surface geometry and boundary condition will be among the factors that affect the heat transfer parameter. 


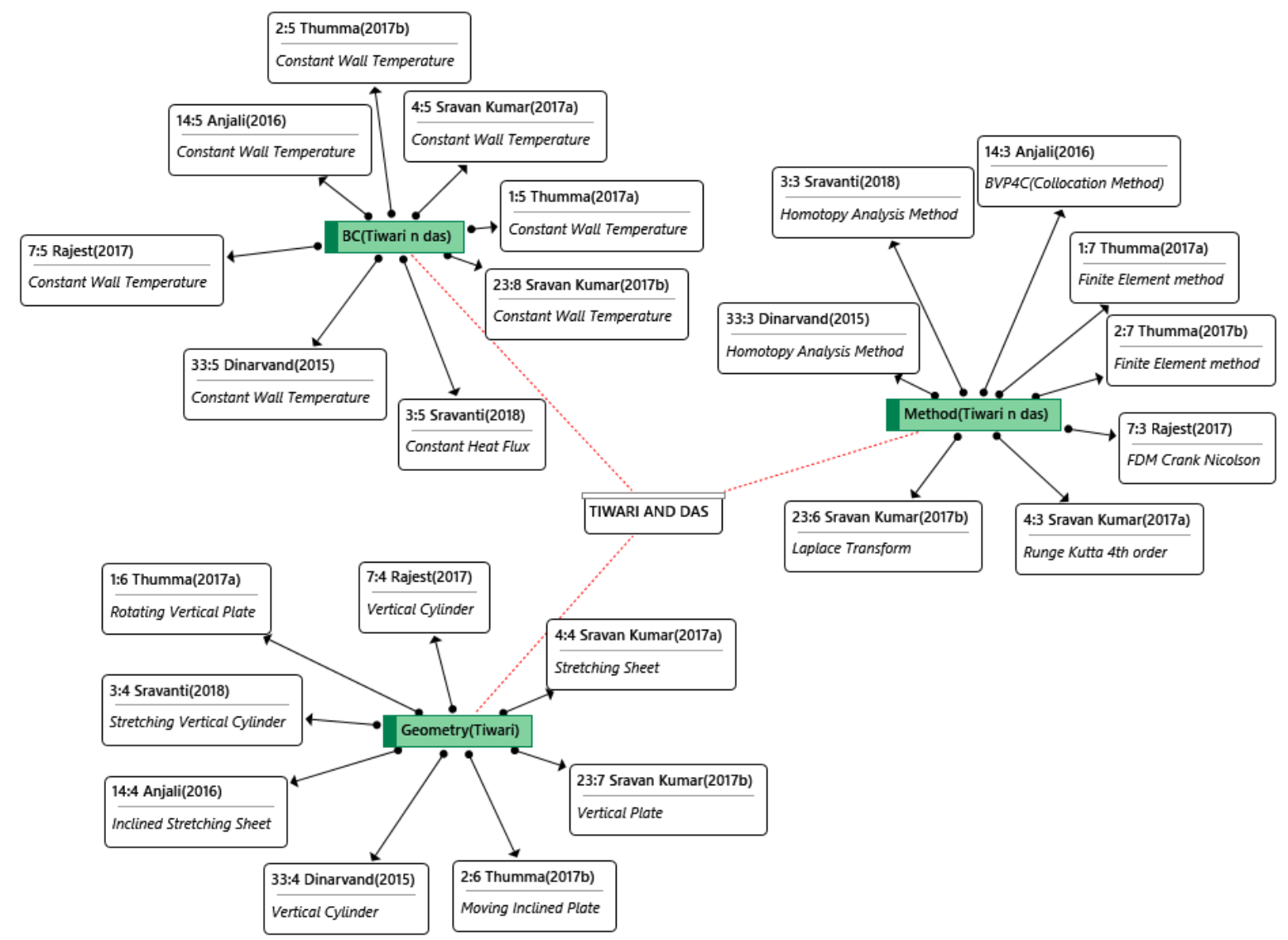

Fig. 7. A network of Tiwari Das model

Table 11

Summary of authors based on boundary condition, geometry and method

\begin{tabular}{llll}
\hline Authors & Boundary Condition & Geometry & Method \\
\hline Dinarvand et al., [68] & CWT & Vertical Cylinder & Homotopy Analysis Method \\
Devi \& Suriyakumar [51] & CWT & Inclined Stretching Sheet & BVP4C (Collocation Method) \\
Rajesh et al., [44] & CWT & Vertical Cylinder & FDM Crank Nicolson \\
Thumma et al., [39] & CWT & Rotating Vertical porous plate & Finite Element Method \\
Thumma et al., [40] & CWT & Moving Inclined porous Plate & Finite Element Method \\
Kumar \& Kumar [42] & CWT & Stretching Sheet & Runge Kutta 4 \\
Kumar \& Kumar [58] & CWT & Vertical Plate & Laplace Transform \\
Sravanthi [41] & CHF & Stretching Vertical Cylinder & Homotopy Analysis Method \\
\hline
\end{tabular}

\subsubsection{Buongiorno}

Buongiorno model is another mathematical model for nanofluid. The network diagram of the Buongiorno model is illustrated in Figure 8. Several papers working on this model are shown in Table 12 , which consider the velocity slip that combines Brownian motion and thermophoresis diffusion parameters. The effect of Brownian motion and thermophoresis parameter were examined by Narahari et al., [45] and Narahari et al., [46] with CWT and CHF, respectively. They investigated the two-dimensional transient natural convective boundary-layer flow past a vertical plate using the Finite-Difference Crank Nicolson method. In another study, Uddin et al., [57] and Sohail et al., [3] discussed the numerical solution of nanofluid over a vertical plate using the FDM Quasi Linear method and Collocation method, respectively, subjected to the CBC. Nayak et al., [62] also explored the steady mixed convective boundary layer flow of nanofluid over a stretching sheet with CBC. This model affects the temperature and concentration profile but not the velocity profile. The literature 
review clearly shows the CWT and CBC considered by many researchers. Nevertheless, the CHF has been given less consideration even this boundary condition is crucial in many industrial and engineering applications.

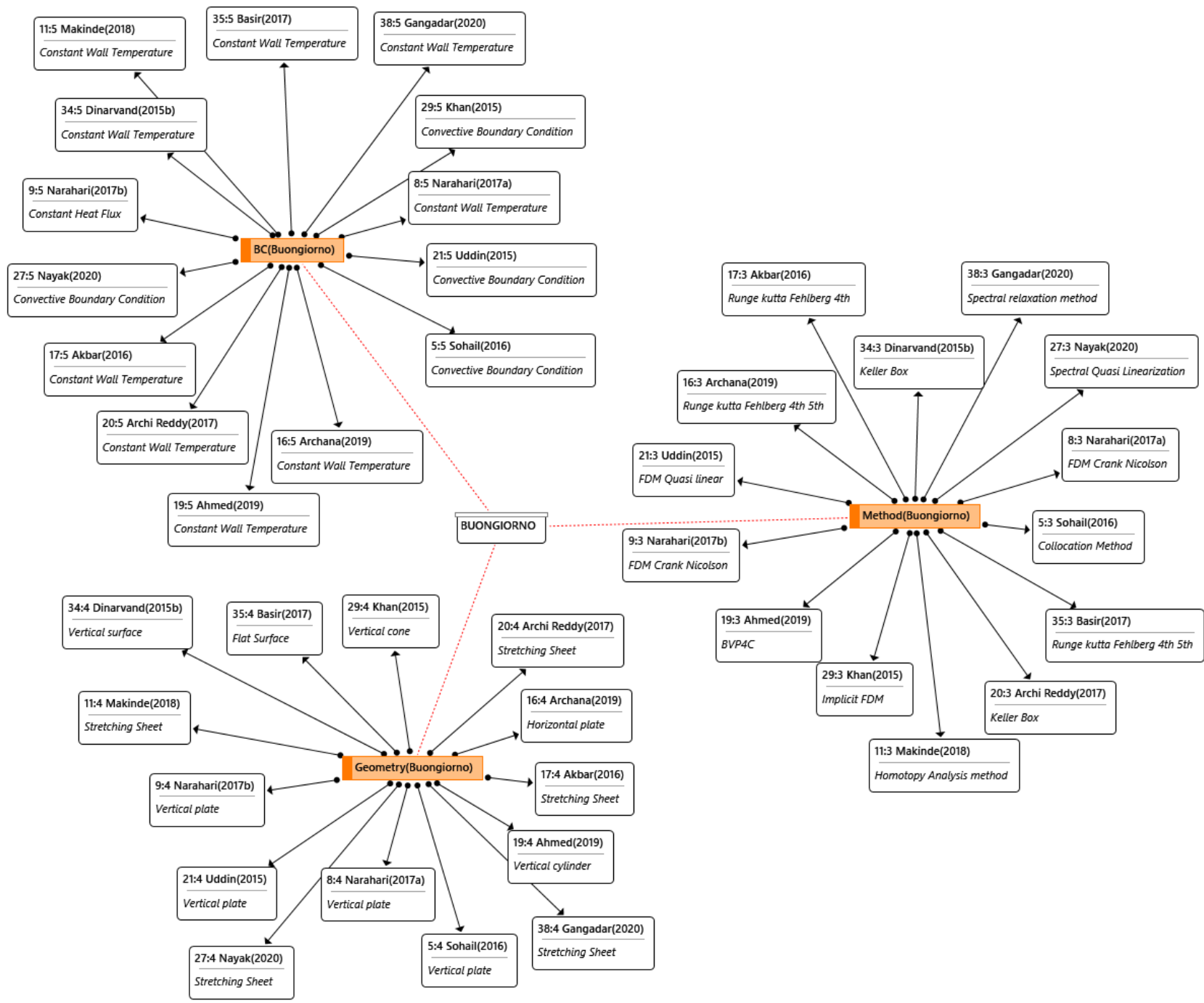

Fig. 8. A Network of Buongiorno model

Table 12

Summary of authors based on boundary condition, geometry and method

\begin{tabular}{llll}
\hline Authors & Boundary Condition & Geometry & Method \\
\hline Dinarvand et al., [69] & CWT & Vertical Surface & Keller Box \\
Khan et al., [64] & CBC & Vertical Cone & Implicit FDM \\
Narahari et al., [45] & CWT & Vertical Plate & FDM Crank Nicolson \\
Uddin et al., [57] & CBC & Vertical Plate & FDM Quasi Linear \\
Akbar et al., [53] & CWT & Stretching Sheet & Runge Kutta Fehlberg $4^{\text {th }}$ \\
Sohail et al., [3] & CBC & Vertical Plate & Collocation Method \\
Basir et al., [70] & CWT & Flat Surface & Runge Kutta Fehlberg $4^{\text {th }} 5^{\text {th }}$ \\
Narahari et al., [46] & CHF & Vertical Plate & FDM Crank Nicolson \\
Reddy \& Shankar [56] & CWT & Stretching Sheet & Keller Box \\
Gangadhar et al., [71] & CWT & Stretching Sheet & Spectral relaxation Method \\
Makinde et al., [48] & CWT & Stretching Sheet & Homotopy Analysis method \\
Ahmed et al., [55] & CWT & Vertical Cylinder & BVP4C \\
Archana et al., [52] & CWT & Horizontal Plate & Runge Kutta Fehlberg $4^{\text {th }} 5^{\text {th }}$ \\
Nayak et al., [62] & CBC & Stretching Sheet & Spectral QuasiLinear \\
\hline
\end{tabular}




\subsection{Hybrid Nanofluid Models}

Recent years have seen a rise in several researches utilising hybrid nanofluid models. When two nanomaterials are suspended into regular fluid, it is known as hybrid nanofluid. Chu et al., [74] studied the hybrid of Molybdenemdisulfide and graphene oxide over an upright cylinder for mixed convection together with thermal radiation effect. The water hybrid nanofluid flow for unsteady natural convection under the radiation and chemical reaction was discussed by [75]. It is found that the heat transfer rate grows by increasing radiation parameter and oscillation frequency. Note that constant wall temperature has been chosen as a preferred boundary condition using the "built-in" bvp4c method to solve the problem. The convective boundary layer problem of hybrid nanofluid has been well described by the researchers, as shown in Table 13.

Table 13

Summary of authors based on boundary condition, geometry and method

\begin{tabular}{llll}
\hline Authors & Boundary Condition & Geometry & Method \\
\hline Chu at al. [74] & CWT & Stretching cylinder & bvp4c \\
Suganya et al., [75] & CWT & Oscillating surface & Laplace Transform \\
Khan et al., [76] & CWT & Shrinking/Stretching Sheet & bvp4c \\
Waini et al., [77] & CWT & Moving Thin Needle & bvp4c \\
Waini et al., [78] & CWT & Shrinking/Stretching Sheet & bvp4c \\
Manjunata et al., [79] & CWT & Stretching Sheet & Runge Kutta Fehlberg \\
Junoh et al., [80] & CWT & Shrinking/Stretching Sheet & bvp4c \\
Rostaimi et al., [25] & CWT & Vertical Plate & bvp4c \\
Yousefi et al., [81] & CWT & Wavy Cylinder & bvp4c \\
Mehryan et al., [82] & CWT & The cavity in porous Media & Finite Element Method \\
\hline
\end{tabular}

\section{Conclusion and Recommendation for Future Studies}

This article reviews the patterns and trends of the mathematical model used in convective boundary layer problems to give researchers some idea in choosing the fluid model that fits the future study. The findings from the code-to-document analysis in ATLAS.ti 8 indicate that the patterns and trends on the mathematical model highlight the boundary condition, different geometry and methods used in the previous study. This paper examines the trends of fluid models by further defining the thematic codes within the fluid models from 2015 to 2020 to assess the models' trends to date.

Based on the findings of this report, there is a void in the study of Brinkman fluid over bluff body with the highlighted boundary condition. It is interesting to be researched due to its imperative applications in porous medium to enhance understanding of fluid flow phenomena. Furthermore, the research output will improve the development of related industries such as engineering equipment and the manufacturing industry. Therefore, it is also a good move to explore the new fluid flow model. In terms of contribution, this review paper provides potential new research of fluid flow model for researchers to explore the gaps that this paper addresses for future studies.

\section{Acknowledgements}

The authors would like to acknowledge the editor and reviewers for their constructive comments and support, which helped us improve the manuscript. The authors also would like to acknowledge The Ministry of Higher Education and Universiti Malaysia Pahang for the financial support through RDU190303 \& The Fundamental Research Grant Scheme for Research Acculturation of Early Career Researchers (FRGS-RACER) (Ref: RACER/1/2019/STG06/UMP//1) through RDU192602. Deep 
appreciation also extended to Universiti Teknologi MARA Cawangan Kelantan, Machang Campus for the guidance and support.

\section{References}

[1] Tlili, Iskander, Masoud Rabeti, Mostafa Safdari Shadloo, and Zahra Abdelmalek. "Forced convection heat transfer of nanofluids from a horizontal plate with convective boundary condition and a line heat source embedded in porous media." Journal of Thermal Analysis \& Calorimetry 141, no. 5 (2020). https://doi.org/10.1007/s10973-020$\underline{09473-6}$

[2] Khan, Z. H., W. A. Khan, and I. Pop. "Triple diffusive free convection along a horizontal plate in porous media saturated by a nanofluid with convective boundary condition." International Journal of Heat and Mass Transfer 66 (2013): 603-612. https://doi.org/10.1016/j.ijheatmasstransfer.2013.07.074

[3] Sohail, Ayesha, M. J. Uddin, and M. M. Rashidi. "Numerical study of free convective flow of a nanofluid over a chemically reactive porous flat vertical plate with a second-order slip model." Journal of Aerospace Engineering 29, no. 2 (2016): 04015047. https://doi.org/10.1061/(ASCE)AS.1943-5525.0000544

[4] Rawi, Noraihan Afiqah, Abdul Rahman Mohd Kasim, Mukheta Isa, and Sharidan Shafie. "g-Jitter induced mixed convection flow of heat and mass transfer past an inclined stretching sheet." Jurnal Teknologi 71, no. 1 (2014). https://doi.org/10.11113/it.v71.3611

[5] Zokri, Syazwani Mohd, Mohd Zuki Salleh, Nur Syamilah Arifin, and Abdul Rahman Mohd Kasim. "Lower stagnation point flow of convectively heated horizontal circular cylinder in Jeffrey nanofluid with suction/injection." Journal of Advanced Research in Fluid Mechanics and Thermal Sciences 76, no. 1 (2020): 135-144. https://doi.org/10.37934/arfmts.76.1.135144

[6] Zokri, Syazwani Mohd, Nur Syamilah Arifin, Abdul Rahman Mohd Kasim, and Mohd Zuki Salleh. "Flow of Jeffrey Fluid over a Horizontal Circular Cylinder with Suspended Nanoparticles and Viscous Dissipation Effect: Buongiorno Model." CFD Letters 12, no. 11 (2020): 1-13. https://doi.org/10.37934/cfdl.12.11.113

[7] Bose, A., N. Nirmalkar, and R. P. Chhabra. "Effect of aiding-buoyancy on mixed-convection from a heated cylinder in Bingham plastic fluids." Journal of Non-Newtonian Fluid Mechanics 220 (2015): 3-21. https://doi.org/10.1016/i.jnnfm.2014.06.006

[8] Zaib, Aurang, and Sharidan Shafie. "Thermal diffusion and diffusion thermo effects on unsteady MHD free convection flow over a stretching surface considering Joule heating and viscous dissipation with thermal stratification, chemical reaction and Hall current." Journal of the Franklin institute 351, no. 3 (2014): 1268-1287. https://doi.org/10.1016/j.jfranklin.2013.10.011

[9] Faizal, Nur Faizzati Ahmad, Norihan Md Ariffin, Yong Faezah Rahim, Mohd Ezad Hafidz Hafidzuddin, and Nadihah Wahi. "MHD and Slip Effect in Micropolar Hybrid Nanofluid and Heat Transfer over a Stretching Sheet with Thermal Radiation and Non-uniform Heat Source/Sink." CFD Letters 12, no. 11 (2020): 121-130. https://doi.org/10.37934/cfdl.12.11.121130

[10] Gireesha, B. J., A. J. Chamkha, S. Manjunatha, and C. S. Bagewadi. "Mixed convective flow of a dusty fluid over a vertical stretching sheet with non-uniform heat source/sink and radiation." International Journal of Numerical Methods for Heat \& Fluid Flow (2013). https://doi.org/10.1108/09615531311323764

[11] Khan, Ansab Azam, Khairy Zaimi, Suliadi Firdaus Sufahani, and Mohammad Ferdows. "MHD Mixed Convection Flow and Heat Transfer of a Dual Stratified Micropolar Fluid Over a Vertical Stretching/Shrinking Sheet With Suction, Chemical Reaction and Heat Source." CFD Letters 12, no. 11 (2020): 106-120. https://doi.org/10.37934/cfdl.12.11.106120

[12] Rawi, Noraihan Afiqah, Abdul Rahman Mohd Kasim, Anati Ali, Mukheta Isa, and Sharidan Shafie. "The effect of gjitter on double diffusion by mixed convection past an inclined stretching sheet." In AIP Conference Proceedings, vol. 1605, no. 1, pp. 392-397. American Institute of Physics, 2014. https://doi.org/10.1063/1.4887621

[13] Mohammad, Nurul Farahain, Iskandar Waini, Abdul Rahman Mohd Kasim, and Nurazleen Abdul Majid. "Unsteady boundary layer flow over a sphere in a porous medium." In AIP conference proceedings, vol. 1870, no. 1, p. 040076. AIP Publishing LLC, 2017. https://doi.org/10.1063/1.4995908

[14] Kasim, Abdul Rahman Mohd, Lim Yeou Jiann, N. A. Rawi, A. Ali, and Sharidan Shafie. "Mixed Convection Flow of Viscoelastic Fluid over a Sphere under Convective Boundary Condition Embedded in Porous Medium." In Defect and Diffusion Forum, vol. 362, pp. 67-75. Trans Tech Publications Ltd, 2015. https://doi.org/10.4028/www.scientific.net/DDF.362.67

[15] Shalini, J. A. I. N., and Shweta BOHRA. "Soret/Dufour Effects on Radiative Free Convection Flow and Mass Transfer over a Sphere with Velocity Slip and Thermal Jump." Walailak Journal of Science and Technology (WJST) 16, no. 9 (2019): 701-721. https://doi.org/10.48048/wjst.2019.3503

[16] Qasim, Muhammad, Tasawar Hayat, and Saleem Obaidat. "Radiation effect on the mixed convection flow of a 
viscoelastic fluid along an inclined stretching sheet." Zeitschrift für Naturforschung A 67, no. 3-4 (2012): $195-202$. https://doi.org/10.5560/zna.2012-0006

[17] Rafique, Khuram, Muhammad Imran Anwar, Masnita Misiran, Ilyas Khan, Sayer O. Alharbi, Phatiphat Thounthong, and Kottakkaran Sooppy Nisar. "Keller-box analysis of Buongiorno model with Brownian and thermophoretic diffusion for Casson nanofluid over an inclined surface." Symmetry 11, no. 11 (2019): 1370. https://doi.org/10.3390/sym11111370

[18] Afridi, Muhammad Idrees, Muhammad Qasim, Ilyas Khan, Sharidan Shafie, and Ali Saleh Alshomrani. "Entropy generation in magnetohydrodynamic mixed convection flow over an inclined stretching sheet." Entropy 19, no. 1 (2017): 10. https://doi.org/10.3390/e19010010

[19] Kasim, Abdul Rahman Mohd, Nur Syamilah Arifin, Syazwani Mohd Zokri, and Mohd Zuki Salleh. "Fluid-particle interaction with buoyancy forces on Jeffrey fluid with Newtonian heating." CFD Letters 11, no. 1 (2019): 1-16.

[20] Zokri, Syazwani Mohd, Nur Syamilah Arifin, Muhammad Khairul Anuar Mohamed, Abdul Rahman Mohd Kasim, Nurul Farahain Mohammad, and Mohd Zuki Salleh. "Mathematical model of mixed convection boundary layer flow over a horizontal circular cylinder filled in a Jeffrey fluid with viscous dissipation effect." Sains Malaysiana 47, no. 7 (2018): 1607-1615. https://doi.org/10.17576/jsm-2018-4707-32

[21] Arifin, Nur Syamilah, Syazwani Mohd Zokri, Abdul Rahman Mohd Kasim, Mohd Zuki Salleh, and Noor Amalina Nisa Arifin. "Jeffrey fluid embedded with dust particles over a shrinking sheet: A numerical investigation." Journal of Advanced Research in Fluid Mechanics and Thermal Sciences 74, no. 2 (2020): 196-209. https://doi.org/10.37934/arfmts.74.2.196209

[22] Al-Sharifi, H. A. M., A. R. M. Kasim, M. Z. Salleh, N. Md Sarif, N. F. Mohammad, S. Shafie, and A. Ali. "Influence of slip velocity on convective boundary layer flow of Jeffrey fluid under convective boundary conditions." ARPN Journal of Engineering and Applied Sciences 11, no. 18 (2006).

[23] Mahat, Rahimah, Noraihan Afiqah Rawi, Abdul Rahman Mohd Kasim, and Sharidan Shafie. "Heat generation effect on mixed convection flow of viscoelastic nanofluid: convective boundary condition solution." Malaysian Journal of Fundamental and Applied Sciences 16, no. 2 (2020): 166-172. https://doi.org/10.11113/mjfas.v16n2.1367

[24] Nagasasikala, Madduleti, and Bommanna Lavanya. "Heat and mass transfer of a MHD flow of a nanofluid through a porous medium in an annular, circular region with outer cylinder maintained at constant heat flux." CFD Letters 11, no. 9 (2019): 32-58.

[25] Rostami, Mohammadreza Nademi, Saeed Dinarvand, and loan Pop. "Dual solutions for mixed convective stagnation-point flow of an aqueous silica-alumina hybrid nanofluid." Chinese Journal of Physics 56, no. 5 (2018): 2465-2478. https://doi.org/10.1016/j.cjph.2018.06.013

[26] Aziz, Laila Amera, Abdul Rahman Mohd Kasim, H. A. M. Al-Sharifi, Mohd Zuki Salleh, Nurul Farahain Mohammad, Sharidan Shafie, and Anati Ali. "Influence of aligned MHD on convective boundary layer flow of viscoelastic fluid." In AIP Conference Proceedings, vol. 1842, no. 1, p. 030005. AIP Publishing LLC, 2017. https://doi.org/10.1063/1.4982843

[27] Kasim, Abdul Rahman Mohd, Mohd Ariff Admon, and Sharidan Shafie. "Free convection boundary layer flow of a viscoelastic fluid in the presence of heat generation." Momentum 10, no. 6 (2011).

[28] Dasman, Anisah, Abdul Rahman Mohd Kasim, Nurul Farahain Mohammad, Aurangzaib Mangi, and Sharidan Shafie. "Mixed convection boundary layer flow of viscoelastic fluids past a sphere." In Defect and Diffusion Forum, vol. 336, pp. 57-63. Trans Tech Publications Ltd, 2013. https://doi.org/10.4028/www.scientific.net/DDF.336.57

[29] Shafie, Sharidan, Muhammad Saqib, Ilyas Khan, and Ahmad Qushairi. "Mixed convection flow of brinkman type hybrid nanofluid based on Atangana-Baleanu fractional model." In Journal of Physics: Conference Series, vol. 1366, no. 1, p. 012041. IOP Publishing, 2019. https://doi.org/10.1088/1742-6596/1366/1/012041

[30] Zakaria, Muhamad Najib, Abid Hussanan, Ilyas Khan, and Sharidan Shafie. "The effects of radiation on free convection flow with ramped wall temperature in Brinkman type fluid." Jurnal Teknologi 62, no. 3 (2013): 33-39. https://doi.org/10.11113/jt.v62.1886

[31] Yasin, Mohd Hafizi Mat, Norihan Md Arifin, Roslinda Nazar, Fudziah Ismail, and loan Pop. "Mixed convection boundary layer flow embedded in a thermally stratified porous medium saturated by a nanofluid." Advances in Mechanical Engineering 2013 (2013): 121943. https://doi.org/10.1155/2013/121943

[32] Hayat, T., S. A. Shehzad, A. Alsaedi, and M. S. Alhothuali. "Mixed convection stagnation point flow of Casson fluid with convective boundary conditions." Chinese Physics Letters 29, no. 11 (2012): 114704. https://doi.org/10.1088/0256-307X/29/11/114704

[33] Arifin, N. S., S. M. Zokri, A. R. M. Kasim, M. Z. Salleh, N. F. Mohammad, and W. N. S. W. Yusoff. "Aligned magnetic field of two-phase mixed convection flow in dusty Casson fluid over a stretching sheet with Newtonian heating." In Journal of Physics: Conference Series, vol. 890, no. 1, p. 012001. IOP Publishing, 2017. https://doi.org/10.1088/1742-6596/890/1/012001

[34] Nadeem, Sohail, Rizwan UI Haq, Noreen Sher Akbar, and Zafar Hayat Khan. "MHD three-dimensional Casson fluid 
flow past a porous linearly stretching sheet." Alexandria Engineering Journal 52, no. 4 (2013): 577-582. https://doi.org/10.1016/i.aej.2013.08.005

[35] Rao, A. Subba, C. H. Amanulla, N. Nagendra, O. Anwar Beg, and A. Kadir. "Hydromagnetic flow and heat transfer in a Williamson Non-Newtonian fluid from a Horizontal circular cylinder with Newtonian Heating." International Journal of Applied and Computational Mathematics 3, no. 4 (2017): 3389-3409. https://doi.org/10.1007/s40819017-0304-x

[36] Arifin, N. S., S. M. Zokri, A. R. M. Kasim, M. Z. Salleh, and N. F. Mohammad. "Aligned magnetic field flow of Williamson fluid over a stretching sheet with convective boundary condition." In MATEC Web of Conferences, vol. 189, p. 11005. EDP Sciences, 2018. https://doi.org/10.1051/matecconf/201818911005

[37] Zairul, Mohd. "A thematic review on student-centred learning in the studio education." Journal of Critical Reviews 7, no. 2 (2020): 504-511. https://doi.org/10.31838/jcr.07.02.95

[38] Clarke, Victoria, and Virginia Braun. "Teaching thematic analysis: Overcoming challenges and developing strategies for effective learning." The psychologist 26, no. 2 (2013).

[39] Thumma, Thirupathi, O. Anwar Beg, and Siva Reddy Sheri. "Finite element computation of transient dissipative double diffusive magneto-convective nanofluid flow from a rotating vertical porous surface in porous media." Proceedings of the Institution of Mechanical Engineers, Part N: Journal of Nanomaterials, Nanoengineering and Nanosystems 231, no. 2 (2017): 89-108. https://doi.org/10.1177/2397791417712856

[40] Thumma, Thirupathi, A. Chamkha, and Siva Reddy Sheri. "MHD natural convective flow of nanofluids past stationary and moving inclined porous plate considering temperature and concentration gradients with suction." International Journal of Numerical Methods for Heat \& Fluid Flow (2017). https://doi.org/10.1108/HFF$\underline{03-2016-0090}$

[41] Sravanthi, C. S. "Slip flow of nano fluid over a stretching vertical cylinder in the presence of non-linear thermal radiation and non-uniform heat source/sink." Scientia Iranica 25, no. 4 (2018): 2098-2110.

[42] Kumar, B., and T. Kumar. "A comparative study of thermal radiation effects on MHD flow of nanofluids and heat transfer over a stretching sheet." Frontiers in Heat and Mass Transfer (FHMT) 9, no. 1 (2017). https://doi.org/10.5098/hmt.9.13

[43] Reddy, P. Bala Anki. "Magnetohydrodynamic flow of a Casson fluid over an exponentially inclined permeable stretching surface with thermal radiation and chemical reaction." Ain Shams Engineering Journal 7, no. 2 (2016): 593-602. https://doi.org/10.1016/i.asej.2015.12.010

[44] Rajesh, V., A. J. Chamkha, Ch Sridevi, and A. F. Al-Mudhaf. "A numerical investigation of transient MHD free convective flow of a nanofluid over a moving semi-infinite vertical cylinder." Engineering Computations (2017). https://doi.org/10.1108/EC-03-2016-0090

[45] Narahari, Marneni, Suresh Kumar Raju Soorapuraju, Rajashekhar Pendyala, and loan Pop. "Transient twodimensional natural convection flow of a nanofluid past an isothermal vertical plate using Buongiorno's model." International Journal of Numerical Methods for Heat \& Fluid Flow (2017). https://doi.org/10.1108/HFF-092015-0394

[46] Narahari, Marneni, S. Suresh Kumar Raju, and Rajashekhar Pendyala. "Unsteady natural convection flow of multiphase nanofluid past a vertical plate with constant heat flux." Chemical Engineering Science 167 (2017): $229-241$. https://doi.org/10.1016/j.ces.2017.04.019

[47] Metri, Prashant G., Pushpanjali G. Metri, Subhas Abel, and Sergei Silvestrov. "Heat transfer in MHD mixed convection viscoelastic fluid flow over a stretching sheet embedded in a porous medium with viscous dissipation and non-uniform heat source/sink." Procedia Engineering $157 \quad$ (2016): 309-316. https://doi.org/10.1016/i.proeng.2016.08.371

[48] Makinde, Oluwole Daniel, Fazle Mabood, and Mohammed S. Ibrahim. "Chemically reacting on MHD boundary-layer flow of nanofluids over a non-linear stretching sheet with heat source/sink and thermal radiation." Therm. Sci. 22, no. 1 (2018): 495-506. https://doi.org/10.2298/TSCI151003284M

[49] Krishna, M. Veera, and M. Gangadhar Reddy. "MHD free convective boundary layer flow through porous medium past a moving vertical platewith heat source and chemical reaction." Materials Today: Proceedings 5, no. 1 (2018): 91-98. https://doi.org/10.1016/i.matpr.2017.11.058

[50] Izani, Siti Nur Haseela, and Anati Ali. "Mixed convective boundary layer flow of a dusty Jeffrey fluid over an exponentially stretching sheet." In AIP Conference Proceedings, vol. 1775, no. 1, p. 030057. AIP Publishing LLC, 2016. https://doi.org/10.1063/1.4965177

[51] Suriyakumar, SP Anjali Deviand P. "Hydromagnetic mixed convective nanofluid slip flow past an inclined stretching plate in the presence of internal heat absorption and suction." Journal of Applied Fluid Mechanics 9, no. 3 (2016): 1409-1419. https://doi.org/10.18869/acadpub.jafm.68.228.24194

[52] Archana, Manjappa, Bijjanal Jayanna Gireesha, and Ballajja Chandrappa Prasannakumara. "Triple diffusive flow of Casson nanofluid with buoyancy forces and nonlinear thermal radiation over a horizontal plate." Archives of 
Thermodynamics 40, no. 1 (2019).

[53] Akbar, Noreen, and S. Nadeem. "Double-diffusive natural convective boundary-layer flow of a nanofluid over a stretching sheet with magnetic field." International Journal of Numerical Methods for Heat \& Fluid Flow (2016). https://doi.org/10.1108/HFF-01-2015-0019

[54] Ahmed, Sameh E., M. A. Mansour, A. Mahdy, and Shadia S. Mohamed. "Entropy generation due to double diffusive convective flow of Casson fluids over nonlinearity stretching sheets with slip conditions." Engineering Science and Technology, an International Journal 20, no. 6 (2017): 1553-1562. https://doi.org/10.1016/i.jestch.2017.10.002

[55] Ahmed, Sameh E., Z. A. S. Raizah, and Abdelraheem M. Aly. "Entropy generation due to mixed convection over vertical permeable cylinders using nanofluids." Journal of King Saud University-Science 31, no. 3 (2019): $352-361$. https://doi.org/10.1016/j.jksus.2017.07.010

[56] Reddy, Ch Achi, and B. Shankar. "Unsteady convective boundary layer of a Nano fluid over a stretching sheet in the presence of Viscous dissipation, Chemical reaction \& Porous Medium." Materials Today: Proceedings 4, no. 8 (2017): 7484-7497. https://doi.org/10.1016/i.matpr.2017.07.080

[57] Uddin, Mohammed J., Waqar A. Khan, and Ahmad Izani Md Ismail. "G-jitter induced magnetohydrodynamics flow of nanofluid with constant convective thermal and solutal boundary conditions." PloS one 10, no. 5 (2015): e0122663. https://doi.org/10.1371/journal.pone.0122663

[58] Kumar, T. Sravan, and B. Rushi Kumar. "Unsteady MHD free convective boundary layer flow of a nanofluid past a moving vertical plate." In IOP Conference Series: Materials Science and Engineering, vol. 263, no. 6, p. 062015. IOP Publishing, 2017. https://doi.org/10.1088/1757-899X/263/6/062015

[59] Saranya, S., P. Ragupathi, B. Ganga, R. P. Sharma, and AK Abdul Hakeem. "Non-linear radiation effects on magnetic/non-magnetic nanoparticles with different base fluids over a flat plate." Advanced Powder Technology 29, no. 9 (2018): 1977-1990. https://doi.org/10.1016/j.apt.2018.05.002

[60] Reddy, M. Gnaneswara. "Unsteady radiative-convective boundary-layer flow of a Casson fluid with variable thermal conductivity." Journal of Engineering Physics and Thermophysics 88, no. 1 (2015): $240-251$. https://doi.org/10.1007/s10891-015-1187-5

[61] Parmar, Amit. "Unsteady convective boundary layer flow for MHD Williamson fluid over an inclined porous stretching sheet with non-linear radiation and heat source." International Journal of Applied and Computational Mathematics 3, no. 1 (2017): 859-881. https://doi.org/10.1007/s40819-017-0387-4

[62] R. E. Nayak, M. V. Rao, and K. Gangadhar. "Mixed convection boundary layer flow of non-newtonian nanofluid using the spectral quasi linearization." Math. Model. Eng. Probl. 7, no. 1 (2020): 45-54. https://doi.org/10.18280/mmep.070106

[63] Maleque, Kh Abdul. "Temperature dependent suction/injuction and variable properties on non-Newtonian Casson mixed convective MHD laminar fluid flow with viscous dissipation and thermal radiation." American Journal of heat and Mass transfer 4 (2017): 104-120. https://doi.org/10.7726/ajhmt.2017.1007

[64] Khan, W. A., M. Jashim Uddin, and A. I. M. Ismail. "Non-similar solution of free convective flow of power law nanofluids in porous medium along a vertical cone and plate with thermal and mass convective boundary conditions." Canadian Journal of physics 93, no. 10 (2015): 1144-1155. https://doi.org/10.1139/cjp-2014-0471

[65] Isa, S. S. P. M., N. M. Arifin, R. Nazar, N. Bachok, F. M. Ali, and I. Pop. "MHD mixed convection boundary layer flow of a Casson fluid bounded by permeable shrinking sheet with exponential variation." Scientia Iranica 24, no. 2 (2017): 637-647. https://doi.org/10.24200/sci.2017.4048

[66] Hamid, Aamir, Masood Khan, and Umair Khan. "Thermal radiation effects on Williamson fluid flow due to an expanding/contracting cylinder with nanomaterials: dual solutions." Physics Letters A 382, no. 30 (2018): 19821991. https://doi.org/10.1016/i.physleta.2018.04.057

[67] Eswaramoorthi, S., M. Bhuvaneswari, S. Sivasankaran, and S. Rajan. "Effect of radiation on MHD convective flow and heat transfer of a viscoelastic fluid over a stretching surface." Procedia Engineering 127 (2015): 916-923. https://doi.org/10.1016/j.proeng.2015.11.364

[68] Dinarvand, Saeed, Abbas Abbassi, Reza Hosseini, and loan Pop. "Homotopy analysis method for mixed convective boundary layer flow of a nanofluid over a vertical circular cylinder." Thermal science 19, no. 2 (2015): 549-561. https://doi.org/10.2298/TSCI120225165D

[69] Dinarvand, Saeed, Reza Hosseini, Milad Abulhasansari, and loan Pop. "Buongiorno's model for double-diffusive mixed convective stagnation-point flow of a nanofluid considering diffusiophoresis effect of binary base fluid." Advanced Powder Technology 26, no. 5 (2015): 1423-1434. https://doi.org/10.1016/i.apt.2015.07.017

[70] Basir, Md Faisal Md, M. J. Uddin, O. Anwar Bég, and AI Md Ismail. "Influence of Stefan blowing on nanofluid flow submerged in microorganisms with leading edge accretion or ablation." Journal of the Brazilian Society of Mechanical Sciences and Engineering 39, no. 11 (2017): 4519-4532. https://doi.org/10.1007/s40430-017-0877-7

[71] Gangadhar, K., T. Kannan, G. Sakthivel, and K. DasaradhaRamaiah. "Unsteady free convective boundary layer flow of a nanofluid past a stretching surface using a spectral relaxation method." International journal of ambient 
energy 41, no. 6 (2020): 609-616. https://doi.org/10.1080/01430750.2018.1472648

[72] Tlili, Iskander. "Effects MHD and heat generation on mixed convection flow of Jeffrey fluid in microgravity environment over an inclined stretching sheet." Symmetry 11, no. $3 \quad$ (2019): 438. https://doi.org/10.3390/sym11030438

[73] Siyal, Ambreen, Kashif Ali Abro, and Muhammad Anwar Solangi. "Thermodynamics of magnetohydrodynamic Brinkman fluid in porous medium." Journal of Thermal Analysis and Calorimetry 136, no. 6 (2019): 2295-2304. https://doi.org/10.1007/s10973-018-7897-0

[74] Chu, Yu-Ming, Kottakkaran Sooppy Nisar, Umair Khan, Hamed Daei Kasmaei, Manuel Malaver, Aurang Zaib, and Ilyas Khan. "Mixed convection in MHD water-based molybdenum disulfide-graphene oxide hybrid nanofluid through an upright cylinder with shape factor." Water 12, no. 6 (2020): 1723. https://doi.org/10.3390/w12061723

[75] Suganya, S., M. Muthtamilselvan, Fahad Al-Amri, and Bahaaeldin Abdalla. "An exact solution for unsteady free convection flow of chemically reacting A 120 3- S i O 2/water hybrid nanofluid." Proceedings of the Institution of Mechanical Engineers, Part C: Journal of Mechanical Engineering Science (2020): 0954406220957710. https://doi.org/10.1177/0954406220957710

[76] Khan, Umair, Anum Shafiq, A. Zaib, and Dumitru Baleanu. "Hybrid nanofluid on mixed convective radiative flow from an irregular variably thick moving surface with convex and concave effects." Case Studies in Thermal Engineering 21 (2020): 100660. https://doi.org/10.1016/i.csite.2020.100660

[77] Waini, Iskandar, Anuar Ishak, and Ioan Pop. "Hybrid nanofluid flow past a permeable moving thin needle." Mathematics 8, no. 4 (2020): 612. https://doi.org/10.3390/math8040612

[78] Waini, Iskandar, Anuar Ishak, and loan Pop. "Unsteady flow and heat transfer past a stretching/shrinking sheet in a hybrid nanofluid." International Journal of Heat and Mass Transfer 136 (2019): 288-297. https://doi.org/10.1016/i.ijheatmasstransfer.2019.02.101

[79] Manjunatha, S., B. Ammani Kuttan, S. Jayanthi, Ali Chamkha, and B. J. Gireesha. "Heat transfer enhancement in the boundary layer flow of hybrid nanofluids due to variable viscosity and natural convection." Heliyon 5, no. 4 (2019): e01469. https://doi.org/10.1016/i.heliyon.2019.e01469

[80] Junoh, Mohamad Mustaqim, Fadzilah Md Ali, Norihan Md Arifin, Norfifah Bachok, and loan Pop. "MHD stagnationpoint flow and heat transfer past a stretching/shrinking sheet in a hybrid nanofluid with induced magnetic field." International Journal of Numerical Methods for Heat \& Fluid Flow (2019). https://doi.org/10.1108/HFF-062019-0500

[81] Yousefi, Mohammad, Saeed Dinarvand, Mohammad Eftekhari Yazdi, and loan Pop. "Stagnation-point flow of an aqueous titania-copper hybrid nanofluid toward a wavy cylinder." International Journal of Numerical Methods for Heat \& Fluid Flow (2018). https://doi.org/10.1108/HFF-01-2018-0009

[82] Mehryan, Seyed AM, Farshad M. Kashkooli, Mohammad Ghalambaz, and Ali J. Chamkha. "Free convection of hybrid Al2O3-Cu water nanofluid in a differentially heated porous cavity." Advanced Powder Technology 28, no. 9 (2017): 2295-2305. https://doi.org/10.1016/i.apt.2017.06.011

[83] Dash, R. K., K. N. Mehta, and G. Jayaraman. "Casson fluid flow in a pipe filled with a homogeneous porous medium." International Journal of Engineering Science 34, no. $10 \quad$ (1996): 1145-1156. https://doi.org/10.1016/0020-7225(96)00012-2

[84] Williamson, R. Vo. "The flow of pseudoplastic materials." Industrial \& Engineering Chemistry 21, no. 11 (1929): 1108-1111. https://doi.org/10.1021/ie50239a035 